\title{
Bernard LEWIS, Les Assassins : terrorisme et politique dans l'Islam médiéval
}

\author{
Gabriel Martinez-Gros
}

\section{(2) OpenEdition}

\section{Journals}

Édition électronique

URL : https://journals.openedition.org/ccm/5398

DOI : $10.4000 / \mathrm{ccm} .5398$

ISSN : 2119-1026

\section{Éditeur}

Centre d'études supérieures de civilisation médiévale/Université de Poitiers

\section{Édition imprimée}

Date de publication : 1 décembre 2020

Pagination : 289-291

ISBN : 978-2-490783-07-6

ISSN : 0007-9731

Référence électronique

Gabriel Martinez-Gros, « Bernard LEwIs, Les Assassins : terrorisme et politique dans I'Islam médiéval », Cahiers de civilisation médiévale [En ligne], 252 | 2020, mis en ligne le 02 décembre 2020, consulté le 23 novembre 2022. URL : http://journals.openedition.org/ccm/5398; DOI : https://doi.org/10.4000/ccm. 5398

\section{(c) (i) $\odot$}

Creative Commons - Attribution - Pas d'Utilisation Commerciale - Pas de Modification 4.0 International - CC BY-NC-ND 4.0

https://creativecommons.org/licenses/by-nc-nd/4.0/ 
Bernard Lewis, Les Assassins : terrorisme et politique dans l'Islam médiéval, A. PÉLISSIER (trad.), M. Rodinson (préf.), Paris, Les Belles Lettres (Le goût de l'histoire, 6), 2019.

Ce sont deux livres en un que nous offre ce petit volume. Le premier, c'est la déjà célèbre étude de Bernard Lewis, l'un des meilleurs orientalistes du siècle passé, sur la secte des Assassins, publié en anglais en 1967. Le second, c'est la préface de 1982 de Maxime Rodinson, grand admirateur du savoir et du talent de B. Lewis, bien qu'il se situât politiquement aux antipodes de l'a.

Commençons par l'essentiel, le texte de B. Lewis, fils de son époque, comme celui de M. Rodinson. Nous sommes en 1966/1967, à l'apogée du tiers-mondisme arabe nassérien et baasiste. La «cause palestinienne» en émerge sous l'impulsion du jeune Arafat. Les mots fidâ', fidayîn, «ceux qui rachètent au prix de leur sacrifice», que le terrorisme des Assassins avait popularisé dans les chroniques, refait surface chez les Palestiniens. C'est probablement l'une des raisons de l'intérêt de B. Lewis pour ce thème. Habilement, l'a. commence par ce que son lecteur occidental sait déjà, ou du moins par ce dont il a vaguement entendu parler. Les Assassins apparaissent dans les chroniques des Croisades au XII et surtout au XIII ${ }^{e}$ s., après leur coup de maître en territoire franc, le meurtre de Conrad de Montferrat, maitre de Tyr et prétendant au trône de Jérusalem en 1192. Le récit principal à leur propos cependant, celui qui reste jusqu'au Alamut de Vladimir Bartol, nous vient de Marco Polo. La secte, dit-il, s'est distinguée par la pratique systématique du meurtre politique, par le poignard et de la main de jeunes gens que le Grand Maître droguait et faisait transporter dans un jardin secret où ils jouissaient de tous les plaisirs, y compris sexuels, du Paradis islamique. Eveillés de ce rêve, ils recevaient de la main du Maître le poignard de leur mission suicide, et la promesse de retrouver après leur mort, une fois leur mission accomplie, ce Paradis dont ils étaient sevrés.

Dès le début du XIX ${ }^{\mathrm{e}}$ s., Silvestre de Sacy confirme qu' «Assassins» vient de Hashishîn, les drogués au hashish, mais relève aussi qu' on ne trouve pas, dans les chroniques arabes, de mention d'une addiction systématique à la drogue chez les jeunes meurtriers. Le terme Hashishîn est arabe, syrien, péjoratif, et ne s'applique jamais à la branche principale, persane, de la secte. Après 1850, les Britanniques retrouvent à Bombay les survivants des Assassins, sous l'autorité d'une dynastie héréditaire de Maîtres nommés, depuis le XIX ${ }^{e}$ s., Aga Khans. Leurs archives sont malheureusement assez minces et surtout indifférentes à l'histoire.
Cette histoire est pourtant immense : c'est celle du shiisme, parti d'Ali dès les premières décennies de l'Islam, et surtout c'est l'histoire des Fatimides, dynastie ismaélienne, du courant intellectuellement le plus avancé du shiisme, qui triomphe d'abord en Ifriqiya/Tunisie en 909 de notre ère, puis en Égypte (969) où elle fonde Le Caire. En l'an Mil, le pouvoir fatimide, étendu de la Sicile et de la Kabylie à l'Euphrate est le plus considérable du monde islamique.

En quoi le shiisme ismaélien est-il avancé ? Hasan-i Sabbah, fondateur de la secte des Assassins, jeune et encore hostile au courant du shiisme auquel il finira par consacrer sa vie, le dit au propagandiste ismaélien qui tente de le convertir à la cause des Fatimides : «Ne me parle pas du Maître du Caire. C'est un philosophe...». Voilà la grande transgression des Ismaéliens pour la majorité sunnite des musulmans : leur ralliement à la science et à la philosophie gréco-arabe, leur subversion du texte coranique et des commandements religieux par des explications rationnelles qui les vident de leur sens et de leur rigueur, leur désinvolture toute "paulinienne» à l'égard de la Loi, leur hypocrisie, la distinction qu'ils font entre la vérité bonne pour les masses, littérale et banale, et celle des élites, ouverte à toutes les spéculations de l'esprit. Étrangement, c'est cette vision du monde très élitiste, très raffinée, qui trouve à s'exprimer par l'extrême violence du terrorisme dirigé contre ses ennemis sunnites, à un moment, il est vrai, à la fin $\mathrm{du} \mathrm{XI}^{\mathrm{e}} \mathrm{s}$., où la partie politique est perdue pour les Fatimides. Depuis le milieu du XI ${ }^{\mathrm{e}}$ s. en effet, le mouvement recule sous la poussée des «peuples nouveaux », Berbères au Maghreb et surtout Turcs en Orient, acquis au sunnisme. La dynastie turque des Seldjoukides conquiert entre 1040 et 1090 la totalité des territoires de l'est de l'Islam, entre Transoxiane et Syrie, y pourchasse et y massacre les Ismaéliens et s'apprête à donner l'assaut à l'Égypte, où s'est retranchée la cause fatimide, quand l'animateur de la politique seldjoukide, le vizir Nizam al-Mulk, est frappé à mort par un Assassin (1092). Quelques semaines plus tard, le sultan Malik Shah meurt à son tour, et l'empire seldjoukide, mal stabilisé, éclate en territoires dissidents et en haines fratricides. Hasan-i Sabbah, l'intellectuel qui a commandité le meurtre, devient le maître incontesté de la mission des propagandistes et des militants ismaéliens clandestins dans tous les territoires seldjoukides. Deux ans plus tard, en 1094, une querelle de succession à la tête du califat fatimide du Caire sanctionne la rupture 
entre un régime épuisé et ses militants de la partie orientale de l'Islam qui affrontent au péril de leur vie le régime turc. Hasan-i Sabbah gagne dans cette rupture sa pleine indépendance.

Mais au talent d'avoir su frapper l'homme qu'il fallait au moment où il fallait, Hasan ajoute d'avoir compris qu'une cause terroriste exige une base, où l'état-major puisse préparer les actions, instruire les militants, accueillir les recrutements. Entre 1090 et 1100, il conquiert une chaîne de châteaux, dans l'extrême nord très montagneux et dans l'est désertique de l'Iran. Il exploite dans les deux cas la détestation pour les Turcs, et le shiisme spontané de populations locales belliqueuses, tard converties à l'islam, dans la première moitié du $\mathrm{X}^{\mathrm{e}} \mathrm{s}$., d'où était issue la dynastie des Bouyides que les Seldjoukides avaient chassée d'Ispahan et de Bagdad. Les Assassins offrent à ces régions une revanche. Jusqu'aux Mongols, nul ne réussira à s'emparer de ces très hautes et étroites vallées, couronnées d'inexpugnables nids d'aigle. Hasan s'installa à Alamut, dans le massif de l'Elbourz, en 1090. Il ne sortira plus jamais de son repaire, jusqu'à sa mort en 1124. Entretemps, plusieurs dizaines de chefs militaires turcs et de juristes sunnites seront tombés sous le poignard. Après sa mort, deux califes abbassides suivront en 1135 et 1138 .

L'épisode le plus spectaculaire de l'histoire de la secte se situe en 1164, quand le quatrième Grand Maître, dans le droit fil du mépris ismaélien des commandements de la Loi coranique, proclame l'abolition de la sharia. En plein mois de Ramadan, pour l'anniversaire de la mort d'Ali, il fait dresser dans la cour du château d'Alamut la table d'un immense banquet où le vin coule à flots parmi les militants, dos tourné à La Mecque.

Tous ne sont pas convaincus. Comme le veut la théorie d'Ibn Khaldûn sur l'usure des dynasties et des causes, le souffle sunnite monté des métropoles finit par toucher Alamut. En 1210, le Grand Maître se rallie au califat abbasside et maudit en chaire Hasan-i Sabbah. Vingt ans plus tard, le calife almohade al-Ma'mûn maudira de même le fondateur de la secte qui a donné le pouvoir à sa lignée, Ibn Tumart. Dans les deux cas, un siècle à peu près s'est écoulé entre l'origine révolutionnaire et son reniement conservateur.

Dans les dernières décennies de son existence (12101256), la secte s'allie aux Abbassides contre les Turcs et face au déferlement mongol, qui l'emporte. Alamut et les principales forteresses tombent en 1256. Le Grand Maître, comme le calife abbasside, est exécuté à coups de masse. Son dernier vizir,
Nasir al-Din Tusi, passe au service des vainqueurs. C'est le plus grand astronome du Moyen Âge. Le dernier chapitre se joue en Syrie, où la secte avait appliqué la même tactique d'acquisition de forteresses inexpugnables et de meurtres politiques, avec moins d'éclat qu'en Iran. Saladin (1174-1193) s'en prémunit en négociant, le mamelouk Baybars l'écrase et la déracine entre 1270 et 1273 .

Un échec, donc, sur lequel médite M. Rodinson en 1982, au crépuscule du communisme dont il fut un militant sans doute moins aveugle que d'autres. Le parallèle qu'il trace entre le shiisme ismaélien et le communisme ne manque pas d'arguments : un même goût de la science et de la pensée, une même méfiance des masses, jamais avouée mais bien présente aussi dans le cas du communisme, une même défaite infligée par la réaction de «petits blancs», dit M. Rodinson non sans anachronisme provocateur. Comme l'Union soviétique au temps du Komintern, le califat fatimide du Caire fut un Etat-Parti : d'une part une domination territoriale, une armée, des finances publiques, une gestion quotidienne; de l'autre, comme les partis communistes dans le monde capitaliste, un peuple de propagandistes et de militants luttant dans un monde hostile. Au xx s. s., l'Union soviétique survécut quelques décennies à la dissolution du Kominform. C'est le contraire dans l'Islam médiéval, où la mission ismaélienne des Assassins survécut presque un siècle à l'État fatimide abattu au Caire par Saladin en 1171 .

Il y a en effet des ressemblances frappantes, et plus de ressemblances en tout cas, entre communisme et fatimisme, qu'entre le communisme et n'importe quel épisode de l'histoire médiévale occidentale. Comme le note bien M. Rodinson, cela tient d'abord à l'existence d'une société urbaine, où le choix politique est abandonné à l'individu, à la différence de la grande masse des sociétés anciennes, où convictions et pratiques «politiques » sont dictées par la naissance et l'appartenance ethnique ou sociale. Dans l'Islam médiéval, la conversion à un parti politique est ouverte. C'est ici cependant que la thèse de M. Rodinson se heurte à des faits contraires. Il est vrai que Hasan-i Sabbah choisit la voie ismaélienne - mais il était né dans un milieu shiite d'une autre nuance, duodécimaine. Et surtout le mouvement fatimide a assuré son triomphe en s'appuyant sur des groupes tribaux dissidents, Kabyles Kutama au $\mathrm{X}^{\mathrm{e}}$ s., montagnards de l'Elbourz et du Kuhistan iraniens au XII ${ }^{\mathrm{e}} \mathrm{s}$.. A l'inverse, les Turcs, contre lesquels il développe une propagande virulente, lui restent étrangers.

Il reste que la thèse touche juste sur un point. L'appareil domestique et militaire du pouvoir dans l'Islam impérial, informé par la pratique de 
l'esclavage militaire, des mamlukks, place les plus hauts dignitaires, princes, vizirs, qadis, entre les mains de serviteurs dont ils ne savent rien des origines - dont on ne doit rien savoir puisque les nouvelles fidélités de l'esclave mamlûk doivent effacer ses attachements antérieurs. Ce qui frappe les chroniqueurs arabes chez les Assassins, c'est moins leur «fanatisme», leur acharnement à mourir et à tuer, que leur capacité à se dissimuler, à se déguiser, à gagner la confiance de leurs victimes. L'hypocrisie supposée du shiisme trouve là son paroxysme. Mais elle est puissamment aidée par un système politique qui ne fait confiance qu'à des étrangers absolus - l'esclave né au loin et qui parle à peine la langue du prince - au détriment des parents et des familiers dont on se méfie. À l'inverse, les Assassins ne peuvent rien contre les rois de France ou d'Angleterre, entourés de compagnons et de serviteurs connus depuis l'enfance. Ils ne peuvent rien non plus contre Templiers ou Hospitaliers, où un
Grand-Maître remplace aussitôt un autre assassiné. Leurs meurtres sont efficaces dans l'Islam parce que le pouvoir y est attaché à une famille au sens large - plusieurs dizaines de prétendants potentiels - sans qu'aucun système de primogéniture fixe la succession. Enfin le terroriste d'il y a huit siècles a la tâche plus difficile que celui d'aujourd'hui. Seul le meurtre d'un Grand porte conséquence politique au XII ${ }^{e}$ s. Le massacre des anonymes laisse indifférent. Dans notre sensibilité démocratique, il suffit au terroriste d'aujourd'hui de déposer sa bombe au milieu de la foule pour faire l'événement et peser sur le cours de l'histoire.

Gabriel MarTinEZ-Gros UMR 8167 - Orient et Méditerranée Université Paris-Ouest Nanterre-La-Défense 